\title{
IV. On electrical expansion
}

\section{Dr. G. Quincke}

To cite this article: Dr. G. Quincke (1880) IV. On electrical expansion, Philosophical Magazine Series 5, 10:59, 30-39, DOI: 10.1080/14786448008626880

To link to this article: http://dx.doi.org/10.1080/14786448008626880

曲 Published online: 28 Apr 2009.

Submit your article to this journal 주다

Џ Article views: 2

Q View related articles $₫$ 
mechanical energy must be applied to the driving-pulley of the electric generator. If the loss so encountered was 40 per cent., as appears to be the case with some of the best machines which have been measured accurately, this would reduce the light developed to 72 candle-power for each horse-power of mechanical energy applied to the driving-pulley of the electric generator.

When we remember that with the arc-light there has been obtained from 1200 to 1800 candle-power per horse-power of mechanical energy applied to the generator, it is evident that Mr. Edison's lamp as now made does not escape the enormous loss which has heretofore been encountered by all forms of incandescent electric lamps.

IV. On Electrical Expansion. By Dr. G. Quincke, Professor of Physics in the University of Heidelberg*".

$A \mathrm{~N}$ extensive research on the action of electricity upon A bodies which conduct badly has given the following results:-

1. Solid and liquid bodies suffer change of volume when they are exposed to the action of electric force in the same way as the glass of a Leyden jar.

2. This change of volume is not caused by change of temperature; generally it is an expansion; but with a few substances, for example with the fatty oils, contraction takes place.

3. No change was observed in the case of air exposed to electric force. If any change of volume occurs, it must be less than $\frac{1}{300} \frac{1}{000000}$ of the original volume.

Alteration of Volume under the Influence of Electricity.

4. The electric expansion of glass is most conveniently observed with a common thermometer, according to the method employed by Fontana $\dagger$, Govi $\ddagger$, and Duter $\$$. The thermometer was placed in a metal vessel filled with melting ice; the liquid inside the thermometer (water, mercury, or saline solutions) formed the inner, the melting ice formed the outer coating of a Leyden jar.

When the two coatings of such a thermometer condenser are placed in communication with an electrical machine charged to a definite amount, or with a larger Leyden jar, the liquid in the tube of the thermometer falls. The level of the

* Translated trom the Berichte der königl. Akademie der Wissenschaften of Berlin, of Feb. 19th, 1880.

$\dagger$ Lettere inedite di Alessandro Volta (Pessro, 1834), p. 15.

$\ddagger$ N. Cim. xxi.-xxii. p. 18 (1865-66). C. $R$. Ixxxvii. 1878, p. 857.

\& C. R. laxxrii, 1878, p. 828. 
liquid in the tube was observed by the aid of a horizontal microscope provided with a micrometer-eyepiece ; and the dimensions of the apparatus were so chosen that a change in volume of $000 \frac{1}{10000}$ of the original volume could be observed.

The change of volume $\Delta v$ is greater the larger the volume $v$ of the bulb of the thermometer is. The change in volume follows instantaneously with flint-glass, more slowly with Thuringian glass (which is a better conductor of electricity). Upon discharge, the fluid returns nearly to its original position, immediately in the case of flint-glass, more slowly with Thuringian glass.

5. The residual displacement (in the same direction as the original displacement) after discharge is very small with flintglass and larger with Thuringian glass, and appears to depend upon the electric polarization of the glass.

6. Under similar circumstances, the change of volume is greater only by an insignificant amount when the thermometer is filled with mercury instead of water.

.7. The volume of the exterior of the thermometer-bulb increases simultaneously with the interior and to the same extent.

8. If the outer surface of the thermometer-bulb be covered with a thin layer of silver, the change of volume produced by electric force is the same, whether the bulb be surrounded by water or by air.

9. This change of volume is almost entirely independent of hydrostatic pressure of the fluid on the walls of the bulb.

10. With the same apparatus, under apparently identical conditions, the change of volume is sometimes greater and sometimes less, according as the glass has remained a longer or a shorter time without being charged with electricity.

11. The expansion $\frac{\Delta v}{v}$ is nearly, but not exactly, proportional to the square of the difference in electric potential of the two coatings of the thermometer-bulb, and inversely proportional to the square of the thickness of the walls of the thermometer-bulb.

With English flint-glass and a thickness of glass of from 0.142 to to 0.591 millim., the change in volume varied from 10.67 to 0.19 millionths of the original volume, with a sparkdistance of 2 millims. between spheres of brass of 20 millims. diameter. With an equal spark-distance, the change in volume for Thuringian glass varied from $4 \cdot 61$ to 0.36 millionths of the original volume with a thickness of glass from 0.238 to $0 \cdot 700$ millim.

With greater change of volume than 10 to 12 millionths of 
the original volume, the glass was generally perforated and the apparatus broken. A change of volume of 68 millionths without fracture was observed only with a particular kind of German glass.

12. Similar changes of volume were observed upon electrifying thermometer condensers of mica, quartz, and caoutchouc filled with water.

The changes of volume observed with many kinds of mica, and with caoutchouc which had remained in contact with water for a long time, were comparable with those observed with glass ; but with fresh caoutchouc the change is about ten times as much.

13. In experiments with vessels of caoutchouc there is observed at the same time a percolation of water through the pores of the caoutchonc under the influence of the electricity.

Alteration of Length under the Influence of Electricity.

14. Narrow glass tubes 1000 to 1200 millims. long were coated inside and out with silver ; the two coatings were insulated from each other and connected with the coatings of a charged Leyden jar. On charging such a tube condenser, expansion took place, which disappeared again almost entirely upon discharge.

The expansion was measured best with Oertling's contactlever, by means of which an expansion of 0.004 millim. could be measured directly, and a tenth of this amount could be estimated with certainty.

The expansion $\Delta l$ of glass rods under electric influence, already investigated by Righi*, takes places essentially according to the same laws as the change in volume of the thermometer condensers. Its magnitude increases with the length $l$ of the rod.

The electric expansion $\frac{\Delta l}{l}$ is nearly, but not exactly, proportional to the square of the difference in electric potential of the coatings of the tube condenser, and inversely proportional to the square of the thickness of the glass. With a difference of potential corresponding to a spark-distance of 2 millims. between brass spheres of 20 millims. diameter, the electric expansion of tubes of English flint-glass varied from 2.26 to 0.72 millionths of the original length for the thickness of glass of 0.097 to 0.186 millim.

15. Under similar circumstances the electric expansion was the same, and attained its maximum in the same time, whether the glass tubes were surrounded with air or water.

* Comptes Rendius, Ixxxviii. 1879, p. 1263. 
16. With the same difference of electric potential,

$$
\text { the inorease in volume } \frac{\Delta v}{v} \text { is, }
$$

for the same kind of glass and the same thickness,

$$
\text { three times the increase of length } \frac{\Delta l}{l} \text {. }
$$

17. The same result was obtained by simultaneous measurement of the increase in volume and the increase in length of a thermometer condenser with a long cylindrical bulb. The bulbs of the thermometer condensers were very uniform tubes of flint-glass, 800 to 1900 millims. in length and 0.362 to 0.621 millim. in the thickness of the glass. The bubble of the spirit-level of the contact-lever was observed with a microscope and micrometer-eyepiece, which permitted the measurement of an increase in length of 0.000008 millim.

18. The relationship $\frac{\Delta v}{v}=3 \frac{\Delta l}{l}$ is not consistent with the hypothesis that the thickness of the glass is diminished by the attraction of the unlike electricities on the coatings of the condenser, and that the volume of the bulb of the thermometer is thus increased indirectly by "electric compression."

19. Electric expansion takes place equally in all directions, in the same way as thermic expansion. The hypothesis that electrio expansion results from heat caused by feeble electric currents traversing the glass between the two coatings is negatived by the facts stated under 6,8 , and 15 .

20. The electric expansion of glass is most simply shown by the use of tubes with excentric bore, in which the glass is thicker on the one side than on the other. Such a tube is curved, after cooling, with the thinner wall on the convex side, since the thicker wall cools more slowly and contracts more forcibly than the thinner wall. Such a glass thread, closed at the lower end, filled with water, and immersed in a deep vessel of water, forms a "glass-thread electrometer," of which the water within and without the tube serves for the coatings.

When these coatings are placed in contact with the coatings of a charged Leyden jar, the thread curves still more, since the thin wall is more expanded by the electric force than the thick wall. The deflection of the glass-thread electrometer may amount to several millimetres, and may be conveniently observed by means of a horizontal microscope with micrometer eyepiece.

Upon discharge, the end of the bent glass thread returns to its original position immediately with flint-glass, more slowly

Phil. Mag. S. 5. Vol. 10. No. 59, July 1880. 
with Thuringian glass. There remains, as with the changes of volume of the thermometer condenser, a residual displace. ment in the same direction as the original displacement, which gradually disappears.

21. With the same glass-thread electrometer, the displacement is proportional to the square of the difference of electric potential of the two coatings.

22. The residual displacement increases with the difference of electric potential and with the conductivity of glass; it seems therefore to depend, like the residual expansion of the the thermometer condenser, on the polarization of the glass.

23 . By means of a suitable key the coatings of the thermometer condenser could be put into communication, first with the poles of a bichromate battery of 44 cells, and then with a sensitive mirror-galvanometer. The deflection of the galvanometer was then proportional to the electric capacity of the thermometer condenser. When the temperature rises, the change of volume corresponding to a given difference of potential is proportional to the increase of electric capacity for the same thermometer condenser.

24. Similarly, the deflections of a glass-thread electrometer, made of the same kind of glass as a thermometer condenser, increase in the same proportion as the electric capacity of the condenser. A temperature-increas $\theta$ of $1^{\circ} \mathrm{C}$. corresponds to an increase of deflection or of capacity of about 0.003 of the original value for flint-glass and about 0.012 for Thuringian glass.

25. The greater the difference of electric potential and the higher the temperature of the glass, the more quickly do the deflections of a glass-thread electrometer take place. Flintglass acts more slowly than Thuringian glass.

\section{Changes of Elasticity caused by Electricity.}

26. The elasticity of flint-glass, Thuringian glass, and caoutchouc is diminished by electricity; but that of mica and guttapercha is increased.

27. A magnetic bar was hung at the lower end of a hollow glass thread silvered inside and outside, so that the magnetic axis was nearly at right angles to the magnetic meridian. The moment of the magnetic force was then equal and opposite to the moment of torsion of the glass thread corresponding to the angle $\phi$ through which it had been twisted.

A vertical mirror was attached to the magnetic bar, whose position was observed with a telescope and scale. When the coatings of the glass thread are connected with the coatings of a charged Leyden jar, the angle of torsion $\phi$ becomes greater by the amount $\Delta \phi$, while the magnetic moment re- 
mains almost unaltered. The increase of the angle $\phi$ corresponds, therefore, to the decrease of the force of torsion of the suspension-thread; and $\frac{\Delta \phi}{\phi}$ is the measure of the change of elasticity of the thread.

Upon discharge, the magnet and thread resume their original position.

The decrease in the force of torsion is nearly proportional to the square of the difference in electric potential of the two coatings, and is greater the less the thickness of the walls of the glass thread.

With a quantity of electricity 20 in the Leyden jar used (of six jars), and a thickness of glass of the suspension-thread 0.1 millim., $\frac{\Delta \phi}{\phi}$ was 0.00055 for flint-glass and 0.002 for Thuringian glass.

An indiarubber tube, gilded on the outside and filled with water, showed with the same Leyden jar about the same change $\frac{\Delta \phi}{\phi}$ as the far thinner thread of Thuringian glass.

28. A strip of mica 840 millims. long, 30 millims. broad, and 0.04 millim. thick, covered with gold leaf on one side and carrying a magnetic bar, in the same way gave an increase of torsion of $\frac{1}{13}$ of the original value when the coated side was connected with the earth, and the uncoated side electrified by means of a metallic comb connected with a Holtz's machine which was passed along it. A band of gutta percha of like dimensions showed under the same circumstances an increase in torsion of 0.00316 of the original value.

29. Similar results were obtained in experiments in which the torsion of the glass thread was balanced by the torsion of a metallic wire.

\section{Electric Expansion of Fluids.}

30. The expansion produced by electric force may be observed with liquids as well as with solids by using a voltameter with platinum electrodes filled with the liquid, the delivery tube of which is replaced by a vertical capillary tube. The apparatus is maintained at a constant temperature by means of melting snow. An increase of volume is observed when the platinum electrodes are connected with the coatings of a charged Leyden jar. When the battery is discharged the fluid returns to its original position in the capillary tabe.

With fluids which are good insulators, such as sulphide of carbon and ethereal oils, the Leyden battery retains its charge 
for some time, and the increase of volume persists for the same length of time; it then disappears gradually. With better conductors (as glycerine, alcohol, and water) the level rises almost instantly, and the battery is discharged immediately.

The same quantity of negative or positive electricity in the Leyden battery gives nearly the same change of volume of the liquid. The change of volume is nearly proportional to $\frac{q^{2}}{s}$ when $q$ denotes the quantity of electricity and $s$ the charged surface of the Leyden jar.

31. With fluids which insulate well, the electrodes may be connected with a Holtz's machine instead of a Leyden battery.

32. With fatty oils which insulate well, a decrease of volume takes place instead of an increase.

33. When the electric charge is too great, a spark passes in the fluid between the platinum electrodes, and the voltameter is broken. Hence the different liquids could not be examined in the same apparatus.

The following table gives an approximate comparison of electric dilatation with thermic dilatation, the expansion being multiplied by $1,000,000$. The electric expansion is that of a layer of substance about 12 millims, in thickness, acted on by the electricity.

$$
\text { Expansion } \frac{\Delta v}{v} \times 10^{6}
$$

\begin{tabular}{|c|c|c|c|}
\hline & \multirow{2}{*}{$\begin{array}{c}\text { By increase of } \\
\text { temperature } \\
\text { from } 0^{\circ} \mathrm{C} \text {. to } 1^{\circ} \mathrm{C} .\end{array}$} & \multicolumn{2}{|c|}{$\begin{array}{l}\text { By a quantity of elec- } \\
\text { tricity. }\end{array}$} \\
\hline & & \pm 20 & \pm 40 \\
\hline Carbon disulphide $\ldots \ldots \ldots \ldots \ldots \ldots$ & 1141 & $5 \cdot 23$ & $22 \cdot 43$ \\
\hline 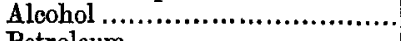 & 1042 & 680 & 35.50 \\
\hline 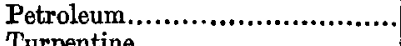 & 1017 & $5 \cdot 66$ & \\
\hline 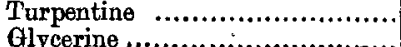 & 902 & $\begin{array}{l}1.70 \\
0.59\end{array}$ & $\begin{array}{r}42 \cdot 45 \\
3 \cdot 19\end{array}$ \\
\hline Distilled water at $8^{\circ} \mathrm{c}$. & $\begin{array}{r}512 \\
92\end{array}$ & 0.07 & 0.23 \\
\hline Water with a trace of hydro- & & & \\
\hline chloric acid at $10^{\circ} \mathrm{C} . \ldots \ldots \ldots \ldots$ & $\ldots$ & $0 \cdot 13$ & $0 \cdot 42$ \\
\hline $\begin{array}{l}\text { Water with } 0.124 \% \text { hydroohloric } \\
\text { acid at } 13^{\circ}\end{array}$ & & 0.07 & 0.56 \\
\hline Distilled water at $0^{\circ} \ldots \ldots \ldots \ldots \ldots$ & -20 & -0.03 & -0.09 \\
\hline Water at $0^{\circ}$ with a trace of hydro- & & & \\
\hline 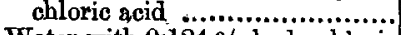 & ...... & -0.06 & $-0 \cdot 30$ \\
\hline $\begin{array}{l}\text { Water with } 0.124 \% \text { hydrochloric } \\
\text { acid at } 0^{\circ} \ldots \ldots \ldots \ldots \ldots\end{array}$ & & -0.03 & -0.33 \\
\hline Thuringian glass .................... & 32 & 0.003 & 0.010 \\
\hline Flint glass $\quad \ldots \ldots \ldots \ldots \ldots \ldots \ldots \ldots \ldots \ldots$ & 26 & 0.002 & 0.009 \\
\hline Colna oil $\ldots \ldots \ldots \ldots \ldots \ldots \ldots \ldots$ & 773 & $-18 \cdot 24$ & ....... \\
\hline Almond oil $\ldots . . . . . . . . . . . . . . . . . .$. & 775 & $-6 \cdot 85$ & ...... \\
\hline
\end{tabular}


It is remarkable that the order of the substances examined, whether they be arranged according to thermic expansion or electric expansion, has no relation to the order of their conductivities for electricity.

34. Changes of temperature of a few hundredths of a degree suffice to bring about the change of volume produced by electricity in the first group of substances, that to which water belongs.

The length of time that the expansion lasts in the case of insulating fluids is opposed to the hypothesis of an indirect expansion, resulting from heat produced by feeble currents of electricity between the electrodes-as is also the small increase of the expansion when the conducting-power of water is increased by the addition of hydrochloric acid, and also the decrease in volume in the case of the fatty oils, which also expand upon increase of temperature from $0^{\circ} \mathrm{C}$.

\section{Electric Perforation of Glass.}

35. Electric force produces generally the same effect as heat, namely expansion. But as by unequal application of heat to different portions of a body it may be broken, so also its fracture may be brought about by the unequal action of èlectric force.

Uniform expansion by heat or by electric force is not capable of fracturing glass; but unequal thermic or electric expansion does so, and the more readily the greater the elastic tension produced in the interior of the glass.

What is true of glass is true of other substances. Thick masses, and such as conduct heat or electricity badly, are fractured more easily than thin masses, or such as conduct heat or electricity readily. This is confirmed by experiment.

\section{Electric Double Refraction.}

36. It is well known that by unequal application of heat solid transparent substances are unequally expanded, and become optically double-refracting.

In the same way, by unequal electric expansion, substances become optically double-refracting. This explains the double refraction observed by Kerr *, which glass, quartz, resin, and insulating fluids exhibit under the influence of electricity, and the apparent contradiction of these results with those obtained by other observers.

If long thin glass plates are coated with tinfoil and power-

* Phil. Mag. (4) 1, pp. 337-348, 446-558, 1875; ib. (5) viii. pp. 85102, 229-245, 1879. 
fully electrified, like a Franklin's plate, there is no double refraction, as was known to me from former experiments, and as also Gordon * and Mackenzie $\dagger$ have found.

The glass is exposed to nearly equal electric force at all points, and uniformly expanded; it is therefore no more doubly refracting than equally heated glass.

But if one of the tinfoil coatings be replaced by mercury in a glass tube of 30 millims. exterior diameter and 14 millims. inner diameter, the end of which has been ground and carefully cemented to the glass plate so that only the glass under the mercury is electrically expanded, the glass is then subjected to unequal electric action, and becomes doubly refracting.

37. If a fluid has heat communicated to particular portions by means of a hot metal plunged in it more quickly than can be conveyed away by conduction and convection, it becomes optically doubly refractive, in the same way as unequally heated glass.

In the same way, a fluid between two metallic electrodes becomes doubly refractive when these are maintained at unequal electric potential. The unequal electric expansion is dependent upon the velocity with which the electricity diffuses itself in the fluid and produces the electric expansion. The expansion is nearly proportional to the square of the electric force active at a given point of the insulator. The expansion must therefore be the greatest along the shortest line of electric force between the electrodes.

Substances whose refractive index increases with increase of temperature, such as glass, and those whose refractive index decrease, such as sulphide of carbon, will behave differently if they are both expanded by electricity and if thermic and electric expansion alter optical properties in the same direction.

In fact, glass and sulphide of carbon show opposed electric double refraction according to the observations of Kerr-a result which my experiments have confirmed.

Further, when substances (such as sulphide of carbon and colza oil) are oppositely affected by electric force, both have their refractive index diminished by thermic expansion; then, again, they must show opposed electric double refraction.

This conclusion also is confirmed by experiment.

38. If a piece of tinfoil be heated by an electric current while between two homogeneous glass cubes, the glass becomes doubly refractive, as if it expanded at right angles to the tin-

* Pbil. Mag. (5) ij. p. 203, 1876. † Wiedem. Ann, ii. p. 356, 1877. 
foil, and contracted parallel to it. The glass behaves like a negative crystal* (Iceland spar) with optic axis parallel to the warmed plate.

The line of greatest heating parallel to the tinfoil or the optic axis of a negative crystal must correspond, in the case of electric double refraction, to the shortest line of electric force between the metallic electrodes, as, in fact, Dr. Kerr $\dagger$ has asserted, and as I have found confirmed.

Moreover those portions of insulators in the neighbourhood of the shortest line of electric force for those substances which Dr. Kerr calls negative (glass, fatty oils, \&c.), behave like optically negative crystals with optic axis parallel to the shortest line of electric force; "positive " substances (sulphide of carbon, \&c.) behave like optically positive crystals with the optic axis parallel to the shortest line of electric force.

More precisely, solid and fluid insulators between metallic electrodes must be regarded as unequally expanded bodies, which act optically like an aggregate of numerous small crystals. The resin called by Dr. Kerr "clear amber resin" behaves oppositely to glass when subjected to electric double refraction, and will probably decrease in volume like the fatty oils under the influence of electric force.

39. The optical phenomena observed with substances which conduct electricity badly, completely confirm the production of expansion and contraction by electric force observed in other ways.

40. The cause of electric expansion and of changes of elasticity produced by electric force is to be sought in a twisting and displacement of the molecules of the insulator-which place themselves with their greatest length in the direction of the resultant electric force, so that their electric moment is a maximum. That small particles of glass and other insulaturs, suspended in badly-conducting fluids, do actually take up such a position, has been shown by Weyl $\ddagger$. If the particles are scattered not in a fluid, but in a mass not perfectly solid, similar changes must take place, but more slowly.

* Compare F. E. Neumann, Abh. Berl. Ak. 1841, ii. p. 6.

$\uparrow$ Phil. Mag. (4) l. p. 337, 1875.

† Reichert and Du Bois's Arch. 1876, p. 721. 